\title{
Effectiveness of kinesiotaping for the treatment of menstrual pain
}

\author{
DOI: https://doi.org/10.5114/pq.2020.96230
}

\author{
Dariusz Boguszewski', Jolanta Borowska', Agata Szymańska', Jakub Grzegorz Adamczyk², \\ Monika Lewandowska', Dariusz Białoszewski' \\ ${ }^{1}$ Department of Rehabilitation, Medical University of Warsaw, Warsaw, Poland \\ 2 Institute of Theory of Sport, Józef Piłsudski University of Physical Education in Warsaw, Warsaw, Poland
}

\begin{abstract}
Introduction. Dysmenorrhoea is a common gynaecological problem among teenage and young adult females. The aim of this work was to evaluate the effectiveness of kinesiotaping for treating menstrual pain.

Methods. The subjects were 44 women with complaints of pain during menstruation. The participants were randomly assigned to 3 groups: group $1(n=16)$, in which a kinesio tape was applied to the abdominal area; group 2 ( $n=14)$, in which an identically looking inelastic tape was applied; and group $3(n=14)$, in which no intervention occurred. The degree of menstrual discomfort was assessed by a visual analogue scale, modified Laitinen questionnaire, and Spielberger state-trait anxiety inventory.

Results. In all groups, within 24 hours after tape application, pain intensity diminished by approximately $50 \%$. In groups 1 and 2 , the reduction of pain occurred 2-4 hours after the application of the tapes. In contrast, in group 3, an initial increase of pain intensity was observed, and pain decrease began after 11 hours. However, the differences between the groups did not reach statistical significance. The values obtained with the Laitinen pain questionnaire revealed that kinesiotaping significantly reduced the intensity $(p=0.004)$ and incidence $(p=0.006)$ of menstrual pain between the first and fifth day.

Conclusions. Painful menstruation severely limits everyday functioning. The application of a kinesio tape to the abdominal area may reduce the severity of pain in women with complaints referring to menstruation.

Key words: kinesiotaping, menstrual pain, painful menstruation, physiotherapy
\end{abstract}

\section{Introduction}

Dysmenorrhoea is the most common gynaecological problem among teenage and young adult females. Severe pain substantially affects quality of life and general well-being and may leave women bedridden for several days [1, 2].

Most women feel pain of some degree during menstruation, the majority on the first day of the period, when bleeding occurs. This is known as primary dysmenorrhoea and is not associated with pathological changes of tissues within the pelvis minor. After the ovulation, progesterone is released at a high concentration from the corpus luteum, which is followed by a release of phospholipid-derived fatty acids. A reaction cascade is initiated in utero leading to the synthesis of prostaglandins and leukotrienes. This can cause inflammation and the development of painful hysterospasms, which can be accompanied by nausea, vomiting, inflations, and headaches. The pain tends to be continuous and radiates to the sacral region. The shrinking uterus can also stimulate its supplying nerves [2-5].

There are several ways of achieving pain reduction during menstruation. The most common approach is the pharmacological one, but several studies have shown non-pharmacological interventions to be efficacious in pain management [2]. Among these, there are heat, rest, and positive thinking $[6,7]$. Some women also use herbal preparations or traditional methods [8]. It has also been demonstrated that kinesiotaping can constitute a simple and relatively cheap form of analgesia [9].

The main objective of the current study was to investigate the influence of kinesiotaping on menstrual pain in young healthy women.

\section{Subjects and methods}

\section{Subjects}

A total of 44 women (volunteers) with complaints of pain during menstruation were included in this study. Their mean age was $22.73( \pm 3.21)$ years. The women were randomly assigned to the following groups:

- group $1(n=16)$ : an elastic K-Active ${ }^{\circledR}$ kinesio tape applied to the abdominal area (Figure $1 \mathrm{~A}$ );

- group $2(n=14)$ : placebo application by using an inelastic tape applied to the same region (Figure 1B);

- group $3(n=14)$ - no intervention.

The groups did not differ significantly in their biometric measures (Table 1).

\section{Treatment and outcome evaluation}

Strips of an elastic kinesio tape (K-Active $\left.{ }^{\circledR}\right)$ or sham tape (Sport Tape ${ }^{\circledR}$ ), $5 \mathrm{~cm}$ wide and multi-coloured, were cut from a roll. Two strips were placed on the skin on the underbelly area, over the pubic joint. One was applied horizontally (from one anterior superior iliac spine to the other) and the second was placed vertically over the first strip, making a cross shape (equidistant from both spines). The third strip was placed on the lumbar section, above the superior iliac spine. The copula technique was used to achieve maximum stretching (100\%) of the kinesio tape. The sham tape was not stretched $[9,10]$.

The subjective intensity of pain was assessed by using a visual analogue scale (VAS). Measurements were recorded at 2-hour intervals for the first 24 hours (except during sleep) and daily for the following 5 days. VAS is a 10-point

Correspondence address: Dariusz Boguszewski, Department of Rehabilitation, Medical University of Warsaw, ul. ks. Trojdena 2C, 02-091 Warsaw, Poland, e-mail: dboguszewski@wum.edu.pl 
A
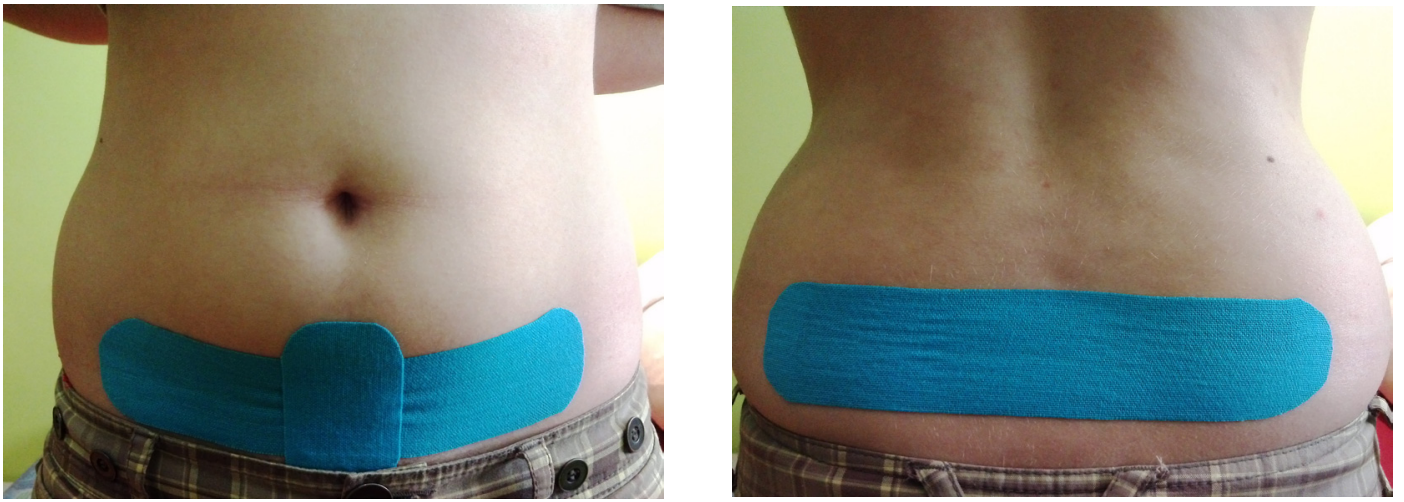

B
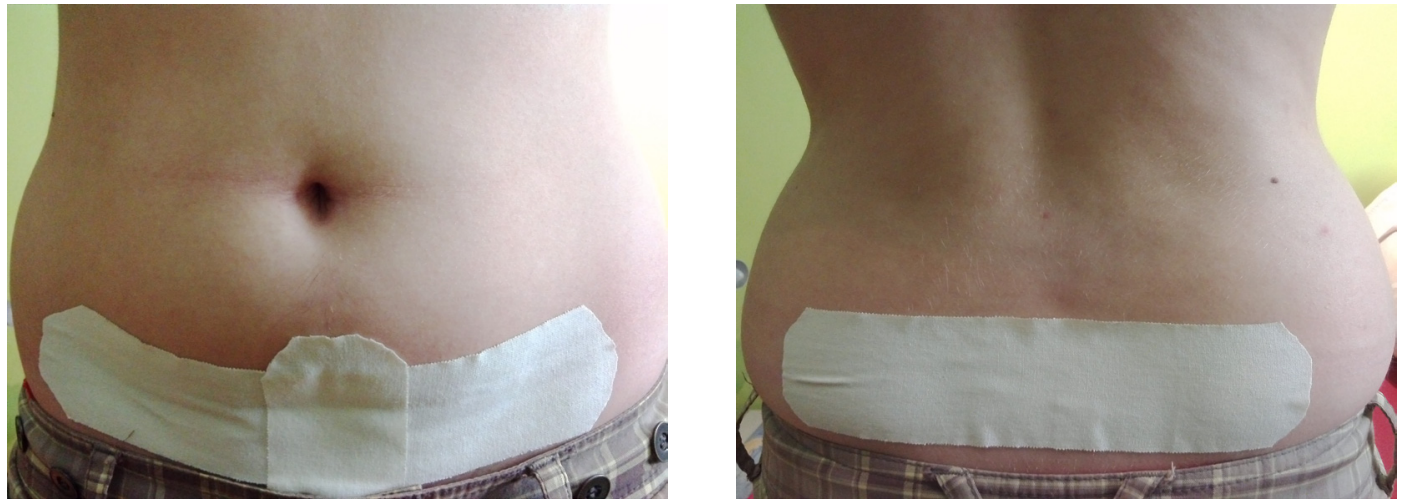

Figure 1. Kinesio tape $(A)$ and placebo $(B)$ application

Table 1. Characteristics of the groups (mean value $\pm S D$ )

\begin{tabular}{|c|c|c|c|c|c|c|}
\hline Group & Age (years) & $\begin{array}{c}\text { Age of menarche } \\
\text { (years) }\end{array}$ & Cycle time (days) & $\begin{array}{l}\text { Duration of men- } \\
\text { struation (days) }\end{array}$ & Body mass (kg) & BMI $\left(\mathrm{kg} / \mathrm{m}^{2}\right)$ \\
\hline 1 & $23.38 \pm 4.77$ & $12.6 \pm 0.95$ & $29.59 \pm 2.11$ & $5.97 \pm 1.19$ & $59.81 \pm 9.28$ & $21.54 \pm 2.58$ \\
\hline 2 & $22.21 \pm 1.72$ & $13.5 \pm 1.45$ & $28.96 \pm 2.63$ & $5.07 \pm 1.02$ & $55.18 \pm 8.38$ & $19.88 \pm 1.88$ \\
\hline 3 & $22.50 \pm 2.03$ & $13.07 \pm 1.54$ & $30.04 \pm 3.91$ & $5.32 \pm 0.93$ & $58.69 \pm 6.75$ & $21.69 \pm 2.51$ \\
\hline
\end{tabular}

scale where a score of 0 indicates no pain and 10 stands for agonizing pain. Pain severity was also evaluated with a modified version of the Laitinen questionnaire, which takes several factors into account, such as pain intensity and frequency, the degree of functional limitation, and the need for administration of analgesic medicines [11].

Anxiety was estimated by using the Spielberger statetrait anxiety inventory (STAI-X1). This questionnaire consists of 20 statements concerning the level of anxiety, to which the subject can respond with one of four answers: 'definitely not,' 'rather not,' 'rather yes,' or 'definitely yes'. The questionnaire was completed on the first and last day of menstruation. A score of 20-80 points could be obtained [12].

Other information was achieved from an initial questionnaire (age, sexual activity, biometrical data, hobbies, diet including dietary supplements, age of first menstruation, length of the menstrual cycle, and the number of days of bleeding).

\section{The investigative procedure}

In group 1, a kinesio tape was applied (Figure 1A) on the first day of menstruation at the moment pain was reported. The copula technique was used to achieve maximum (100\%) tape stretching. Two tapes, one horizontally and one vertically, were stuck on the underbelly region. One tape was placed horizontally on the sacral region [10].
On the first day of the study, the women completed an initial questionnaire concerning age, body mass index, age of first period, physical activity, hobbies, diet, and limitations of motor activity during menstruation. They also filled in the modified Laitinen and STAI-X1 questionnaires. During the initial 24 hours, a VAS pain score was recorded every 2 hours (with the exception of sleep). For the next 5 days, the subjects provided a VAS score once daily, at approximately the same time each day. On the fifth day, the participants completed the second modified Laitinen and STAI-X1 questionnaires and also a final questionnaire which sought to identify any inconveniences associated with the tapes (e.g. allergy or constraint of movement).

The women from group 2, in which sham tapes were applied (Figure 1B), and those from the control group underwent identical investigative procedures.

The subjects who received tapes were instructed about how to nurse the areas where the tape had been applied for the duration of the study.

\section{Statistical methods}

Statistical analyses were conducted with the Statistica software, version 12 . The scores were statistically analysed. The normality of distribution was determined by the ShapiroWilk test. The significance of differences between the results 
of the first and second measurements (Laitinen and Spielberger questionnaires) were determined with the Wilcoxon signed-rank test. Changes in VAS scores were examined by using the Friedman's ANOVA test with post-hoc testing via Fisher's least significance difference. Between-group differences were assessed with the Mann-Whitney $U$ test. Statistical significance was set for all statistical procedures at $p \leq 0.05$.

\section{Ethical approval}

The research related to human use has complied with all the relevant national regulations and institutional policies, has followed the tenets of the Declaration of Helsinki, and has been approved by the authors' institutional review board or an equivalent committee.

\section{Informed consent}

Informed consent has been obtained from all individuals included in this study.

\section{Results}

On the first day of menstruation (immediately before the application of the kinesio or placebo tape), the average intensity of pain, based on the VAS scale, was $6.17( \pm 2.36)$ in group 1, $4.86( \pm 2.48)$ in group 2, and $4.61( \pm 3.48)$ in group 3. To eliminate differences in baseline measures, data were normalized to this initial score (which was taken as 100\%). In all the groups, pain intensity decreased by approximately $50 \%$ in the first 24 hours. In groups 1 and 2, pain reduction occurred almost immediately, within 2-4 hours after the tape application $(p<0.001)$. In contrast, in group 3 , an initial increase in pain intensity was reported, followed by a decrease from the 10-hour time point. However, the differences between the groups did not reach statistical significance (Figure 2).

The intensity of pain in groups 1 and 3 diminished at a similar rate in the following 5 days (ANOVA $p<0.001$ ). The rate of pain intensity decrease was more rapid in these groups compared with group 2 . The greatest reduction in pain intensity (about $60 \%$ ) was found on the third day. In group 2 , on the same day we observed a less substantial reduction (about 30\%) in pain (Figure 3).

The analysis of data obtained from the modified Laitinen questionnaire revealed that kinesiotaping significantly reduced the intensity $(p=0.004)$ and frequency $(p=0.006)$ of menstrual pain between the first and fifth day. In the kinesiotaping group, lower scores were also found in measures assessing the need for analgesic medicines $(p=0.011)$ and limitation of physical activity $(p=0.034)$. It should be noted that we also observed a significant decrease in pain intensity $(p=0.049)$ in group 2 (Table 2).

The level of anxiety connected with pain during menstruation was estimated with the use of the STAI-X1 questionnaire. The average anxiety in group 1 and 2 before tape application was $43.13( \pm 11.21)$ and $44.71( \pm 13.31)$, respectively. The score for group 3, where no tapes were applied, equalled 41.36 ( \pm 14.76$)$. After the kinesio tape application, the level of anxiety in group 1 significantly decreased $(p=0.008)$. There were no significant differences in the remaining groups (Table 2).

\section{Discussion}

Gynaecological problems are quite often described in the scientific literature [13-15]. One of them is painful menstruations. This type of pain tends to be primal (physiologi-

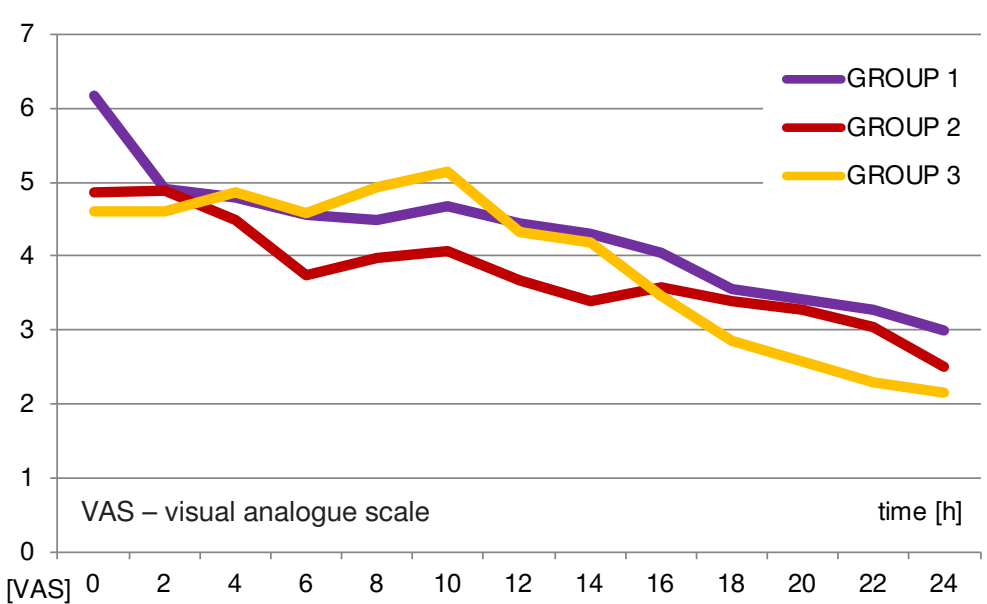

Figure 2. Pain intensity (measured by VAS) in the first 24 hours

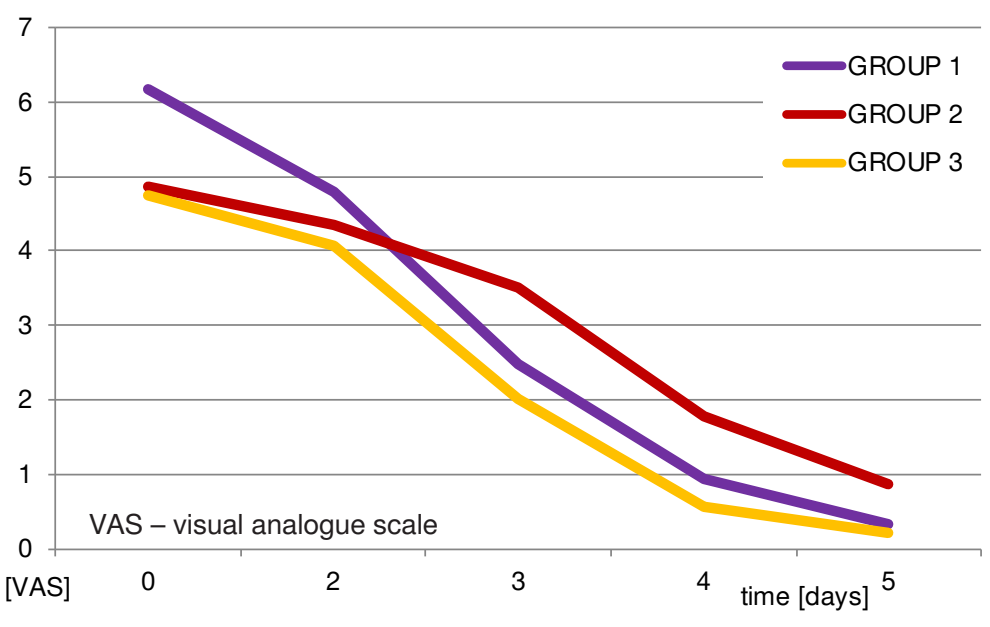

Figure 3. Pain intensity (measured by VAS) in 5 days 
Table 2. Characteristics of pain (measured by the Laitinen scale) and anxiety level (measured by the Spielberger questionnaire)

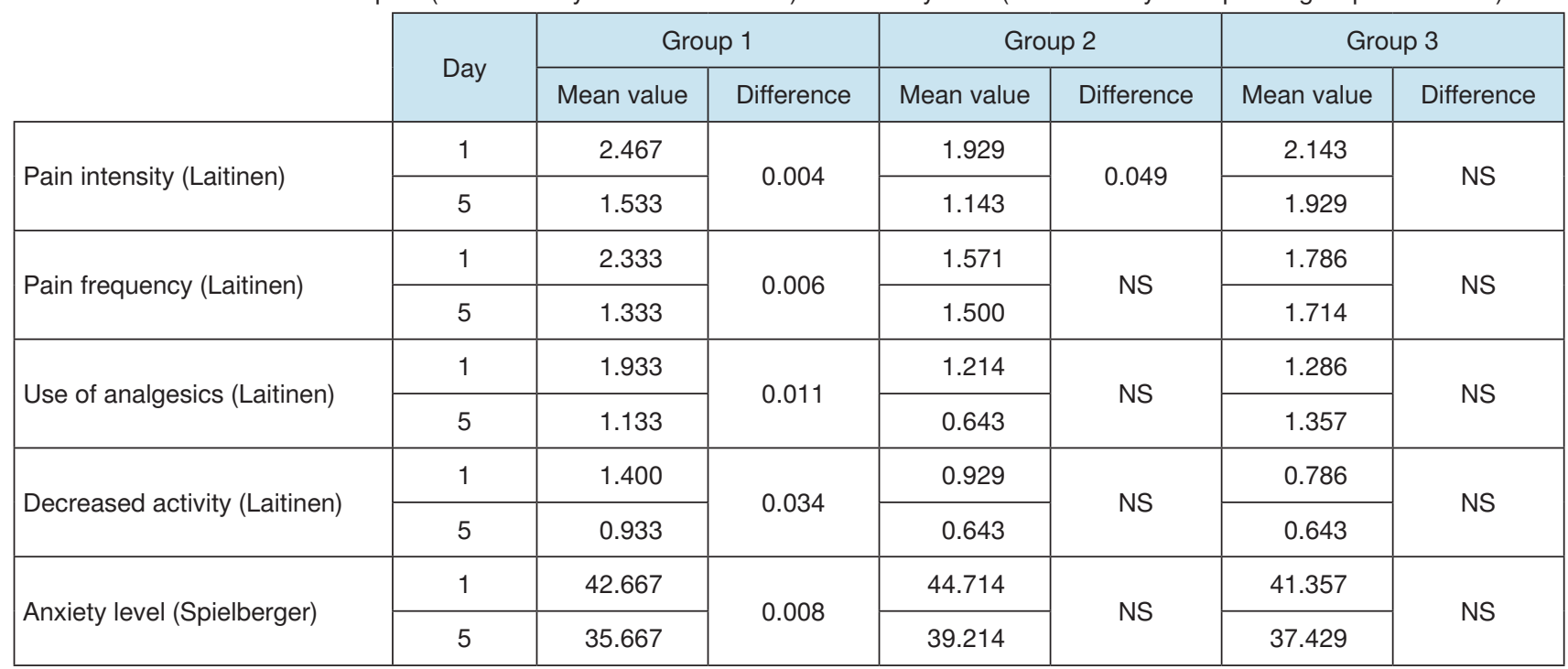

NS - not significant

cal) in character and is not associated with any pathology of the organs in the pelvis minor [2].

Overproduction of prostaglandins and leukotrienes are thought to play a key role in the pathogenesis of menstrual pain. Harel et al. [16] compared urinary leukotriene levels at the time of menstruation in women reporting painful menstruations and those without pain. They found that higher concentrations of leukotrienes were associated with painful menstruations, which indicates that these inflammatory mediators may participate in pain-generating processes.

Non-pharmacological methods used to treat menstrual pain include exercises, acupressure, fomentations, and dietary supplements [5, 17-19]. A study of Japanese teenagers revealed that traditional medicine, Toki-shakuyaku-san, effectively reduced menstrual pain [8]. Omidvar et al. [20] demonstrated in a group of 50 women that a capsule of dill extract taken 4 times a day for 3 days during menstruation reduced pain in comparison with placebo applied in the control group. Proctor et al. [21] also indicated an effective menstrual pain control obtained with percutaneous nerve stimulation.

The therapeutic benefits of non-steroidal analgesic medicines, as well as oral and injectable contraceptives on menstrual pain are widely known [22-24]. However, the potential impact of kinesiotaping on menstrual pain has been very rarely investigated [25-28]. This prompted us to examine the effectiveness of this method in the control of complaints during menstruation. We found that the application of a kinesio tape reduced the subjective feeling of pain during menstruation. The decrease did not occur immediately, since equivalent degrees of pain were reported across all groups on the first day; rather, the application was beneficial after several days. Our results also show that the kinesio tape application reduced anxiety in women. Kinesio tape application was also associated with a reduced need for analgesic medication and improved motor activity in group 1 as compared with groups 2 and 3 .

Future studies should be directed towards verification of the data presented in this study by using a larger sample population and also by introducing more objective investigative tools (e.g. the measurement of underbelly muscle tone or thermography) $[29,30]$. It may also be advisable to introduce a degree of subjects' pseudorandomization, such as assigning experimental groups after baseline data have been gathered and analysed. This would ensure that baseline values (in this case, pain) are properly balanced across all groups and would help avoid instances of group participants differing considerably in their baseline score, as was the case in this study.

In summary, the application of a kinesio tape is an efficient method for controlling menstrual pain among young women. This approach could be an effective alternative to pharmacological interventions, which are often associated with adverse events.

\section{Conclusions}

1. Kinesio tape application appears to reduce the severity of pain in women with complaints regarding menstruation. This observation was chiefly based on a decrease in the need for analgesic medication and in the limitation of motor activity.

2. Sham taping produced a similar but weaker therapeutic effect (namely, it reduced pain severity and the usage of analgesic medicines).

3. Kinesiotaping was also beneficial at decreasing the level of anxiety associated with pain and discomfort during menstruation.

4. Research on the effectiveness of kinesiotaping for the reduction of menstrual pain requires further studies using objective investigative tools (e.g. the measurement of underbelly muscle tone or thermography).

\section{Disclosure statement}

No author has any financial interest or received any financial benefit from this research.

\section{Conflict of interest}

The authors state no conflict of interest.

\section{References}

1. Harel Z. Dysmenorrhea in adolescents and young adults: etiology and management. J Pediatr Adol Gynec. 2006; 19(6):363-371; doi: 10.1016/j.jpag.2006.09.001.

2. Weisberg E, McGeehan K, Fraser IS. Effect of perceptions of menstrual blood loss and menstrual pain on women's quality of life. Eur J Contracept Reprod Health Care. 2016; 21(6):431-435; doi: 10.1080/13625187.2016.1225034. 
3. Kannan P, Chapple CM, Miller D, Claydon LS, Baxter GD. Menstrual pain and quality of life in women with primary dysmenorrhea: rationale, design, and interventions of a randomized controlled trial of effects of a treadmill-based exercise intervention. Contemp Clin Trial. 2015;42:8189; doi: 10.1016/j.cct.2015.03.010.

4. Forozeshfard M, Bakhtiary AH, Aminianfar A, Sheikhian S, Akbarzadeh Z. Short term effects of kinesio taping on pain and functional disability in young females with menstrual low back pain: a randomised control trial study. J Back Musculoskelet Rehabil. 2016;29(4):709-715; doi: 10.3233/BMR-160673.

5. Yonglitthipagon $P$, Muansiangsai S, Wongkhumngern W, Donpunha W, Chanavirut R, Siritaratiwat W, Mato L, Eungpinichpong W, Janyacharoen T. Effect of yoga on the menstrual pain, physical fitness, and quality of life of young women with primary dysmenorrhea. J Bodyw Mov Ther.2017;21(4):840-846; doi:10.1016/j.jbmt.2017.01.014.

6. Campbell MA, McGrath PJ. Use of medication by adolescents for the management of menstrual discomfort. Arch Pediatr Adolesc Med. 1997;151(9):905-913; doi: 10.1001/archpedi.1997.02170460043007.

7. Campbell MA, McGrath PJ. Non-pharmacologic strategies used by adolescents for the management of menstrual discomfort. Clin J Pain. 1999;15(4):313-320; doi: 10.1097/00002508-199912000-00008.

8. Kotani N, Oyama T, Sakai I, Hashimoto H, Muraoka M, Ogawa Y, Matsuki A. Analgesic effect of an herbal medicine for treatment of primary dysmenorrhea - a doubleblind study. Am J Chin Med. 1997;25(2):205-212; doi: 10.1142/S0192415X9700024X.

9. Tittinger R, Słoniak T. Rehabilitation taping [in Polish]. Rzeszów: Fizjoterapia Rafał Słoniak; 2012.

10. Kase K. Kinesio taping perfect manual. Tokyo: Kinesio Taping Association; 2012.

11. Korzeniowska K, Szałek E. The pain [in Polish]. Farm Wspol. 2010;3:9-14.

12. Wrześniewski K, Sosnowski T, Matusik D. State-trait anxiety inventory (STAI): the Polish adaptation [in Polish]. Warszawa: Pracownia Testów Psychologicznych PTP; 2002.

13. Bobowik PŻ, Dąbek A. Physiotherapy in women with diastasis of the rectus abdominis muscles. Adv Rehab. 2018;3:11-18; doi: 10.5114/areh.2018.80964.

14. Gruszczyńska D, Truszczyńska-Baszak A. Exercises for pregnant and postpartum women with diastasis recti abdominis - literature review. Adv Rehab. 2018;3:27-35; doi: 10.5114/areh.2018.80967.

15. Chen HM, Hu HM. Randomized trial of modified stretching exercise program for menstrual low back pain. West J Nurs Res. 2019;41(2):238-257; doi: 10.1177/019394 5918763817.

16. Harel Z, Lilly C, Vaz R, Riggs S. Urinary leukotriene (LT)-E4 in adolescents with dysmenorrhea. J Adolesc Health. 2000; 27(3):151-154; doi: 10.1016/s1054-139x(00)00123-3.

17. Chang EA, Koo IS, Choi JH. The effect of Pilates stabilization exercise and kinesio taping on the dysmenorrhea and prostaglandin F2 $\alpha$ of female university students. J Int Acad Phys Ther Res. 2018;9(3):1558-1563; doi: 10.20540/JIAPTR.2018.9.3.1558.

18. Samy A, Zaki SS, Metwally AA, Mahmoud DSE, Elzahaby IM, Amin AH, Eissa Al, Abbas AM, Hussein AH, Talaat $B$, Ali AS. The effect of Zumba exercise on reducing menstrual pain in young women with primary dysmenorrhea: a randomized controlled trial. J Pediatr Adolesc Gynecol. 2019;32(5):541-545; doi: 10.1016/j.jpag.2019.
19. Taylor D, Miaskowski C, Kohn J. A randomized clinical trial of the effectiveness of an acupressure device (relief brief) for managing symptoms of dysmenorrhea. J Altern Complement Med. 2002;8(3):357-370; doi: 10.1089/ 10755530260128050.

20. Omidvar S, Esmailzadeh S, Baradaran M, Basirat Z. Effect of fennel on pain intensity in dysmenorrhoea: a placebo-controlled trial. Ayu. 2012;33(2):311-313; doi: 10.4103/0974-8520.105259.

21. Proctor ML, Smith CA, Farquhar CM, Stones RW. Transcutaneous electrical nerve stimulation and acupuncture for primary dysmenorrhea. Cochrane Database Syst Rev. 2002;1:CD002123; doi: 10.1002/14651858.CD002123.

22. Davis AR, Westhoff C, O'Connell K, Gallagher N. Oral contraceptives for dysmenorrhea in adolescent girls: a randomized trial. Obstet Gynecol. 2005;106(1):97-104; doi: 10.1097/01.AOG.0000165826.03915.65.

23. Alsiyabi AIS, Mullaicharam AR, Halligudi N. A review on evaluation, management and pathophysiology of dysmenorrhea. World J Pharm Res. 2016;5(5):241-259; doi: 10.20959/wjpr20165-6100.

24. Davis S. Menstrual pain - when to eliminate and when to investigate. S Afr Pharm Assist. 2018;18(1):13-14.

25. Tomás-Rodríguez MI, Palazón-Bru A, Martínez-St John DRJ, Toledo-Marhuenda JV, Del Rosario Asensio-García M, Gil-Guillén VF. Effectiveness of medical taping concept in primary dysmenorrhoea: a two-armed randomized trial. Sci Rep. 2015;5:16671; doi: 10.1038/srep16671.

26. Wilk T, Niewęgłowska-Wilk M, Załęska I. Kinesiology taping as an alternative to painkillers used for the reduction of menstrual pains. Pol J Physiother. 2015;15(4):82-88.

27. Yum KS, Kang SG, Han HJ. The effect of balance taping for prevention of menstrual pain in female middle school students. J Phys Ther Sci. 2017;29(5):813-818; doi: 10.1589/jpts.29.813.

28. Guruprasad P, Sharma U, Palekar T. Immediate effect of yoga postures $\mathrm{v} / \mathrm{s}$ physiotherapy exercises along with k-taping on pain in dysmenorrhea. Int J Sci Res Sci Technol. 2019;6(2):487-494; doi: 10.32628/IJSRST196290.

29. Adamczyk JG, Krasowska I, Boguszewski D, Reaburn P. The use of thermal imaging to assess the effectiveness of ice massage and cold-water immersion as methods for supporting post-exercise recovery. J Therm Biol. 2016;60:20-25; doi: 10.1016/j.jtherbio.2016.05.006.

30. Adamczyk JG, Gryko K, Boguszewski D. Does the type of foam roller influence the recovery rate, thermal response andDOMSprevention?PLoSOne.2020;15(6):e0235195; doi: 10.1371/journal.pone.0235195. 